\title{
Test development and use in five Iberian Latin American countries
}

\author{
Solange M. Wechsler ${ }^{1}$, Thomas Oakland ${ }^{2}$, Carmem León ${ }^{3}$, Eleonora Vivas ${ }^{4}$, \\ Leandro de Almeida ${ }^{5}$, Amanda Franco ${ }^{5}$, María Pérez-Solís ${ }^{6}$, and Norma Contini ${ }^{7}$ \\ ${ }^{1}$ Departamento de Psicologia, Pontificia Universidade Catolica de Campinas, São Paulo, Brazil \\ ${ }^{2}$ International Foundation for Children's Education, Gainesville, FL, USA \\ ${ }^{3}$ Centro de Formación e Investigación Humanística, Universidad Catolica Andres Bello, Caracas, \\ Venezuela \\ ${ }^{4}$ Departamento de Ciencia y Tecnologia del Comportamiento, Universidad Simon Bolivar, \\ Caracas, Venezuela \\ ${ }^{5}$ Departamento de Psicologia da Educação, Universidade do Minho, Braga, Portugal \\ ${ }^{6}$ Departamento de Psicologia Evolutiva y de la Educación, Universidad Complutense de Madrid, \\ Madrid, Spain \\ ${ }^{7}$ Facultad de Psicologia, Universidad Nacional de Tucumán, Buenos Aires, Argentina
}

\begin{abstract}
7 he abundance of scholarship on test development and use generally is higher in English-speaking than in Iberian Latin American countries. The purpose of this article is to help overcome this imbalance by describing and identifying similarities and differences in test development and use in two Iberian (Portugal and Spain) and three of the largest Latin American (Argentina, Brazil, and Venezuela) countries. The stages of test development in each country, roles of professional associations, presence of standards for test use, professionals' educational training, commonly used tests, together with prominent challenges to continued progress are discussed. Test development and use in these five countries are transitioning from a dependence on the use of translated tests to greater reliance on adapted and finally nationally constructed tests. Continued growth requires adherence to international standards guiding test development and use. Stronger alliance among professional associations in the Iberian Latin American countries could serve as a catalyst to promote test development in these regions.
\end{abstract}

Keywords: Psychological assessment; South America; Iberian America; Test; Test adaptation.

Test development and use reportedly constitutes applied psychology's most important contribution to behavioural sciences. Their use provides one of the most common and important services to society (Geisinger, 2013). Test development and use emerged in China approximately 3000 years ago, largely remained dormant for centuries in other counties, and then emerged somewhat strongly in some Western countries in the twentieth century (Shiraev, 2011). Conditions external and internal to psychology affect its growth (Oakland, 2009). External conditions over which psychology has little control include a country's economic infrastructure and wealth as well as public attitudes towards individual differences. Internal quality over which psychology has more control includes the presence and strength of professional associations in psychology, professional standards and the quality of undergraduate and graduate education (Muñiz \& Bartram, 2007). An understanding of the status of qualities over which psychology has control enables us to determine the success of our history and to identify areas requiring growth.

Test use is universal, yet far from uniform among more than 200 countries (Oakland, 2004). Its use is most apparent in Australia, Canada, Israel, South Africa, United States and most Western European countries. Less is known about its development and use in African, Asian, Iberian Latin American and Middle Eastern countries (Muñiz et al., 2001; Oakland, Wechsler, \& Maree, 2013). Additionally, the development and clinical use of tests is more common for children and youth than for adults, with tests that assess cognitive and personality traits used most commonly for them (Gregory, 2010).

Correspondence should be addressed to Solange Muglia Wechsler, Departamento de Psicologia, Pontificia Universidade Catolica de Campinas, Campus II, Av. John Boyd Dunlop, Campinas 13060-904, Sao Paulo, Brazil. (E-mail: wechsler@lexxa.com.br). 
Most countries display limited ability to develop their own tests and instead import tests developed elsewhere. These imported tests typically are translated into the local language while some are adapted for local use and possibly normed (Muñiz \& Fernández-Hermida, 2000; Wechsler et al., 2010). Psychologists in most developed countries usually believe that their tests meet existing professional standards, whereas those in emerging countries realise their tests do not display sufficient high standards (Ever et al., 2011). Criticisms in these latter countries focus on low professional standards for test development and use, together with inadequate training for providing assessment services.

Technical standards for test development and use exist. Examples include Standards for Educational and Psychological Testing (American Educational Research Association, American Psychological Association, National Council on Measurement in Education, 1999) and the European Federation of Psychologists' Associations' European Standard for Test Use (www.efpa.eu/ professional-development/assessment). The International Test Commission has also established test guidelines, including those on test adaptations, test use and computer-based and Internet-delivered testing (http:// www.intestcom.org). Lamentably, ethical standards for test use are found in only 35 countries (Leach \& Oakland, 2007). Although psychological assessment in Iberian Latin American countries has to an extent a rich history (Wechsler, 2013), scholarship that appears in widely circulated English language journals on test development and use in most of these countries is limited yet required.

The purpose of this article is to summarise key features of test development and use in three of the largest countries in Latin America (Argentina, Brazil and Venezuela) and two Iberian Latin countries (Portugal, Spain). They share similar languages and cultural backgrounds. Resemblances and differences in test use in these countries are described, especially in reference to the stages of test development, roles of scientific associations, professional training, standards for test development and commonly used tests. Prominent challenges to continued progress are also identified and discussed.

\section{TEST DEVELOPMENT AND USE IN ARGENTINA}

Psychology departments in Argentine universities commonly emphasise psychological assessment and diagnosis. Psychologists' training and practice have gone through two stages. At first, psychoanalytic theory, models and methods permeated clinical and research practices, in part, due to the widespread development, acceptance and prestige of projective assessment techniques during the first half of the twentieth century. The use of the Rorschach Test exemplifies this stage and led to the formation of the Asociación Argentina de Psicodiagnóstico de Rorschach (Argentine's
Rorschach Association) in 1952 and a scientific journal Psicodiagnostico de Rorschach y Otras Tecnicas Projectivas (Rorschach Psychodiagnosis and Other Projective Techniques), as mentioned by Contini (2013).

A second stage emerged during the last 20 years due to the growth of norm-referenced tests, an increased popularity of psychological assessment and increased acceptance of higher psychometric standards. This movement stimulated the adaptation of some Spanish versions of tests and others from English-speaking countries (Casullo, 1996). An increase in test use in both clinical practice and research led to the formation of the Asociación Nacional de Estudios y Investigaciones in Psicodiagnostico-ADEIP (National Association of Studies and Research on Psychodiagnostic) in 1988 and the Asociación Iberoamericana de Diagnóstico y Evaluación Psicológica-AIDEP (Iberian American Association of Diagnosis and Psychological Assessment) in 1995 (www.aidep.org). Both associations meet regularly, bring together national and international experts, and thus provide favourable environments to disseminate information on test development and use.

\section{Professional standards}

Bachelor-level training generally qualifies psychologists to use tests. However, recognising that additional training often is needed to use tests competently, universities began offering more specialised postgraduate courses and degrees since the 1990s. The National Ministry of Education characterised psychological studies as risky because they affect human health. Thus, psychologists are required to engage in pre-professional practices in psychological assessment in order to further develop and evaluate their assessment skills. Argentina lacks legal standards governing test use. Although psychology professional associations emphasise the importance of the ethical use of tests, they lack legal authority to exercise control over those who misuse tests (Casullo, Figueroa, \& Aszkenazi, 1991).

\section{Commonly used tests}

Among norm-referenced measures, the Bender Gestalt Test (with Koppitz's scoring method used with children) and the Wechsler scales of intelligence are among the most popular measures. Despite growing reliance on norm-referenced and to some degree behavioural assessment methods, projective tests still are preferred among many psychologists (Ávila Espada \& Rodríguez, 1992). The availability of the Exner scoring method added to the Rorschach's reliability and further enhanced its use.

\section{Developmental needs}

Trends in test development and use include required improvements in test development, including test 
validation, together with more rigorous research on issues important to clinical, occupational, educational and forensic assessment practices. Additionally, the discipline of psychology is both growing and consolidating, moving away from qualitative research that relies heavily on case studies towards quantitative methods that yield representative national norms.

\section{TEST DEVELOPMENT AND USE IN BRAZIL}

The history of test development and use in Brazil can be characterised in three stages. In stage one, during the late nineteenth century, tests were imported from the United States and Western European countries and usually were valued. In 1914, a psychological laboratory was organised in Sao Paulo. The period between the 1950 s and 1960s was very productive as many tests that assess intelligence, other aptitudes and personality were developed. A 1962 federal law authorised the profession of psychology to have exclusive use of psychological assessments (Pasquali, 2010).

During the second stage, test use fell out of favour. During the 1970s, despite of the growth of university programmes that offered psychology courses, opposition to tests increased among professionals. Tests that had been translated or adapted usually faced criticism for not being developed originally in Brazil (Hutz, 2009). In addition, norm-referenced measures were viewed as discriminatory by highlighting individual differences - a view then inconsistent with widely accepted public policy. The use of projective measures for clinical use was viewed as more acceptable. Consequently, test development stagnated until the 1980s (Wechsler, 2013).

More positive attitudes towards tests emerged by 1980, thus characterising a third stage in test development. Brazilian psychologists began responding to criticisms towards the tests by investing efforts in test construction and adaptation. University-based psychology researchers created psychometric laboratories dedicated to the construction, adaptation, validation and standardisation of tests in light of Brazilian reality. The 1989 founding of the Brazilian Institute for Psychological Assessment-Instituto Brasileiro de Avaliacao Psicológica (www.ibapnet.org.br) and the creation of the journal Avaliacao Psicologica (Psychological Assessment) have had a positive and instrumental impact on the development of psychological tests (Primi, 2010).

\section{Professional standards}

In 2001, the Federal Council of Psychology defined standards for test quality. Its impact was also instrumental. For example, all tests used in Brazil must present evidence of their validity, reliability and national norms. A commission of national experts reviews and evaluates tests. The
Federal Council of Psychologists' website lists the current 130 approved tests that can be used by psychologists in clinical practice (http://www2.pol.org.br/satepsi/sistema/ admin.cfm?lista2=sim\#).

\section{Commonly used tests}

Commonly used internationally developed and subsequently locally adapted, validated and normed tests include the Wechsler Intelligence Scales for Children (WISC-III), Bender Gestalt Test, Raven Progressive Matrices, Human Figure Drawing and House-Tree-Person.

\section{Developmental needs}

There are 120 masters and doctoral level psychology programmes recognised by the federal agency Coordenacao de Aperfeicoamento do Pessoal de Nivel Superior (www.capes.gov.br/cursos-recomendados). Despite the availability of graduate preparation, an undergraduate degree in psychology constitutes the entry level for those who use tests. Efforts are needed to encourage further improvements in test practice. These include elevating the entry level for psychological practice beyond an undergraduate degree and improving the training of psychologists to use test. Additional tests for use with special needs children as well as for personnel selection and management are needed (Oakland et al., 2013). Language proximity and cultural similarities enable Brazil to help promote test development and use in other Latin American countries.

\section{TEST DEVELOPMENT AND USE IN PORTUGAL}

Psychology was introduced into Portugal universities in 1975. Prior psychological services largely were limited to the assessment of intelligence in special education, for recruitment and professional selection (e.g. in the armed forces). Thus, both the discipline and practices within psychology, including psychological assessment, are more recent and thus less developed in Portugal compared to most Western European countries (Almeida \& Franco, 2010).

The availability of psychological tests occurred in three stages. During the first stage, prior to the 1970s, several foreign-developed tests of intelligence and personality were available. They generally did not meet adaptation and validation standards and some were normed for use in special education and military selection. During the second stage, from the mid-1970s through the 1980s, validation studies, typically completed as part of theses and dissertations, focused on construct validity and cultural equivalence. Finally, during the third and current 
state, Portuguese psychologists became more committed to using more stringent methods to adapt some of the more widely used foreign-developed tests as well as to develop new tests and other assessment methods, including behavioural and clinical instruments (Almeida, Prieto, Muñiz, \& Bartram, 1998).

\section{Professional standards}

Prior to 2006, entry level to practice psychology required a 5-year degree in psychology. Then the acceptance of the Bologna Plan led to a two-stage preparation process: the first 3 years for undergraduate psychology courses and an optional two additional years for a master's degree. Students are introduced to psychological assessment during the master's degree, with primary emphasis placed on diagnostic, intervention issues and secondary emphasis on psychometric issues.

\section{Commonly used tests}

Educational/school psychologists use psychological tests to assess students' cognitive and learning abilities, assist in providing personal and vocational consultation and evaluate the results of intervention programmes. The most frequently used tests for children and youth include the WISC-III, Wechsler Preschool and Primary Scale of Intelligence-Revised, Raven Progressive Matrices, a few national batteries of cognitive tests and checklists designed to assess self-concept, study methods, behavioural problems and vocational or motivational aspects. The assessment of specific aptitudes for use in vocational guidance with adolescents and young adults occurs with the use of the Portuguese versions of Primary Mental Abilities test and the General Aptitude Test Battery.

\section{Developmental needs}

Portuguese psychologists are aware of limitations associated with psychological tests, especially the limited number of standardised instruments, the lack of current versions of some widely used tests internationally, as well as outdated validity data and norms of some commonly used tests. Additionally, few tests are available to assess children with special needs or those from minority groups. The widespread use of questionnaires that have meager psychometric qualities to assess personality is particularly troubling.

Psychology training typically focuses on theoretical information and the use of specific assessment methods. However, student training often is superficial and does not include current psychometric methods and applications of reliable and validated data (Diniz, Almeida, \& Pais, 2007). Additionally, students have limited opportunities to acquire foundation assessment skills important to their work with people from minority groups or with special education needs, resulting in a lack of competence to serve adequately a culturally diverse society. Existing adapted and validated tests often are not revised, thus limiting their relevance. Moreover, available regulations consistent with international standards that guide assessment practices need to be used.

\section{TEST DEVELOPMENT AND USE IN SPAIN}

Psychological assessment enjoys considerable support within psychology and the Spanish public. Test development followed two main stages. During the first stage, foreign-developed tests usually were adapted and typically used with adults in work and labour settings. By 1953, psychological assessment was promoted as part of the scientific discipline at Madrid's School of Applied Psychology and Psychotechnics. During the 1970s, psychological assessment advanced further through the work of the Spanish Society for Rorschach as well as the publication of Psicodiagnóstico Clinico (Clinical Psychological Assessment), a compendium of 125 Spanish assessment instruments (Alvarez, 1972). Adaptations of some widely used international scales (e.g. the Wechsler tests of intelligence) occurred in response to needs in educational and clinical practices.

The second stage, characterised by expansion and exchange, was ushered in by the First Congress of Psychological Assessment in 1984, which led to the formation of the Spanish Society of Psychological Assessment in 1985 and soon its scholarly journal Evaluación Psicológica (Psychological Assessment). During this period, the use of behavioural assessments became more prominent. However, these measures often did not display suitable psychometric standards. Thus, psychologists retained their interest in the use of conventional norm-referenced measures.

\section{Professional standards and leadership}

In 1990, the Spanish Society of Psychological Assessment agreed to help provide leadership for psychological assessment in Europe (Carpintero, 1989). This led to the transformation of this Society to the European Association of Psychological Assessment and the formation of its scholarly journal, the European Journal of Psychological Assessment. Additionally, several European Commissions on which Spanish psychologists played an important role led to the development of guidelines and standards for test adaptation and use (www.cop.es). Psychologists' professional training, which was limited to 5-year undergraduate level, changed in response to the Bologna Plan to a 3-year undergraduate degree and an optional 2-year master's degree. 


\section{Commonly used methods}

A 1999 study of attitudes of Spanish psychologists toward psychological assessment found them generally to be positive towards test use as well as the need to improve assessment training (Muñiz \& FernándezHermida, 2000). A similar study conducted 10 years later acquired European psychologists' views towards tests. Again, psychologists viewed test use and assessment practices positively. They also indicated better legal and professional standards were required to further improve testing practices. Educational and school psychologists were identified as the largest test consumers and relied heavily on paper and pencil tests. Among the more than 500 psychological tests published and used in Spain, 140 were created by Spanish authors to serve the needs of educational, clinical and to a lesser extent organisational psychologists (Prieto \& Muñiz, 2000).

\section{Developmental needs}

Thus, although considerable progress has been made in the construction, distribution, adaptation and use of tests and other assessment methods in Spain, additional attention is needed to strengthen standards for test use, professional preparation and professional regulation. These efforts will benefit from associations with others countries in order to establish common international professional guidelines.

\section{TEST DEVELOPMENT AND USE IN VENEZUELA}

Psychological assessment in Venezuela has gone through three stages of development. At first, tests mainly were imported from other countries and merely translated into Spanish. Little attention was paid to their psychometric qualities, including the need for national norms. A second stage occurred when tests were adapted to Venezuelan culture and validated. Current psychological assessment practices embody a mixture of both the first and second stages plus the use of scales and tests that have been produced locally, mainly in universities and consulting organisations

\section{Professional standards}

The 1978 Psychology Practice Act regulates applications of psychological instruments. However, the law does not restrict the use of tests to psychologists or the use of adapted tests (Leon, Silva, \& De Llano, 2008). Venezuelan universities play a leading role in the production and promotion of scholarship on and undergraduate training in psychological assessment. The country's eight schools of psychology share a theoretical and practical curriculum that includes undergraduate courses in statistics, psychometrics, psychological assessment, as well as testing theory and specific assessment instruments. There are no graduate courses on psychological assessment.

\section{Commonly used tests}

A study of the status of psychological assessment (Vivas, 2000) obtained the views of 380 Venezuelan psychologists regarding the use of tests and other assessment methods. The most frequently used were interviews (97\%), projective techniques (72\%), observation $(67 \%)$ and objective (e.g. normed) tests $(66 \%)$, followed by non-normed nor validated scales, questionnaires and games. Owing to cultural differences within the Venezuelan population, adjustments to test scores are made somewhat routinely in light of a person's cultural diversity, language, socioeconomic differences, urban/rural background, cultural traditions and religion.

Issues of test availability influence services in psychological assessment. Venezuela lacks a commercial infrastructure commonly found in advanced countries, one that distributes and sells a wide range of quality tests. Additionally, due to the country's unstable economy during the last 11 years, few psychologists are able to purchase tests developed abroad. These and other conditions have led to the development of many locally developed standardised questionnaires, scales and other assessment procedures that may have adequate validity and reliability for research or consulting purposes, yet lack norms and sufficiently high reliability and validity expected globally in test construction to warrant their clinical use. The use of paper and pencil and easily photocopied tests could account for the wide and frequent use of projective techniques. They usually are not interpreted from a psychodynamic perspective and instead in more free ways that suit the individual assessment specialist.

\section{Developmental needs}

Improvements to psychological assessment in Venezuela will require greater congruence between paradigm, theory, methodology and testing instruments. Resources among universities need to be shared and better utilised and joint efforts encouraged. The Venezuelan Psychological Association should provide stronger leadership concerning standards for test construction and use. Assistance from regional and international organisations could help achieve these goals.

\section{DISCUSSION}

Proper test use constitutes one of psychology's most important services to society; their use is widespread (Geisinger, 2013; Shiraev, 2011). Test development and use are impacted by many qualities over which the 
profession has control, including the presence of one or more strong professional associations that advocate for high standards for test development and use as well as desired minimum, yet acceptable, entry standards for those who provide assessment services (Muñiz \& Bartram, 2007; Oakland, 2004). The histories of test development in Iberian (Portugal and Spain) as well as in Latin American (Argentina, Brazil and Venezuela) countries reflect the importance of these resources (Muñiz \& Fernández-Hermida, 2000; Wechsler et al., 2010).

During the last century, test development and use in these five countries usually followed one of two paths: either a preference for theory-based tests, often of a psychoanalytic nature, or greater reliance on test adaptation. The preference for projective tests under a psychoanalytic interpretation remains common in Argentina and Venezuela, especially the use of the Rorschach test (Contini, 2013; Vivas, 2000). In contrast, test use in Brazil, Portugal and Spain is more psychometric oriented, including a heavy reliance on adaptations of US developed tests, including the Wechsler intelligence scales for children and adults and the Raven Progressive Matrices (Almeida \& Franco, 2010; Muñiz \& Fernández-Hermida, 2000; Wechsler, 2013).

All five countries generally displayed a desire to transition from reliance on translated tests to both adapted and locally developed tests. This movement is best defined in Brazil and Spain. Psychologists there led efforts to ensure tests reflected local conditions, thus adding significantly to the number of locally developed tests. These efforts require considerable local technical resources, including professionals with considerable expertise in psychometrics. They are in short supply in Argentina and Venezuela and, until recently, in Portugal and Spain, wherein the requirements to enter the profession are higher after implementing the Bologna Plan (Ever et al., 2011).

The wise use of tests requires well-educated practitioners. This standard is not attained through a general undergraduate degree in psychology - an all too common standard in most of these countries (Oakland, 2009). The positive impact of professional association efforts to improve the quality of assessment activities is most apparent in Brazil by the Brazilian Institute of Psychological Assessment, and Spain by the European Association of Psychological Assessment, both publishing important scientific journals (Muñiz \& Bartram, 2007; Primi, 2010). Their efforts provide a model for possible use in the other three countries. Additionally, universities and professors can also play an instrumental role in promoting test development and use.

Efforts are needed to establish suitable universitybased programmes when they do not exist and to strengthen those that do. All five countries recognise the teaching mission of a university should be consistent with international standards. These countries also acknowledge the importance of knowing and adhering to strong international and regional standards for test development and use, including the guidelines from the International Test Commission (Hambleton, Bartram, \& Oakland, 2011; Prieto \& Muñiz, 2000), European Federation of Psychologists' Associations' European Standard for Test Use and Standards for Educational and Psychological Testing (American Educational Research Association, American Psychological Association, National Council on Measurement in Education, 1999). Standards from Brazil also could serve other countries well. Knowledge of these standards will assist in efforts to develop the knowledge and skills needed within a country to engage in test development and use (Leach \& Oakland, 2007). Expertise from countries that are members of the International Union of Psychologist could also assist in these required developmental efforts.

Psychologists in all five countries face challenges to their efforts. These include the need to develop and use assessment methods that are sensitive to cultural differences and that serve the needs of their respective societies. The goal to describe accurately personal behaviours in ways that are linked to cultural characteristics remains important (Oakland et al., 2013). This attitude is worthy of continued pursuit and consistent with well-defined ethical obligations to serve society well. However, economic and social disparity issues generally weigh heavily on these efforts, as test development is affected by a country's economic infrastructure and wealth (Oakland, 2009).

Newer methods and models that serve to jumpstart and support test development efforts are needed. For example, the greater use of the Internet to deliver courses that promote an understanding and use of advanced psychometric methods could help overcome the current shortage of psychometric specialists found commonly in most countries. Additional professional support from public, private and professional sectors is also needed. The profession of psychology, including its testing practices, is stronger in countries with well-established professional associations. Further actions to create and strengthen professional associations devoted to test development and use are needed at the national and regional levels. A stronger alliance among professional associations in Argentina, Brazil, Portugal, Spain and Venezuela could provide leadership that could lead to material improvements in testing resources as well as the promotion of test development and use in other South as well as Central American countries.

Manuscript received August 2013 Revised manuscript accepted March 2014 First published online May 2014

\section{REFERENCES}

Almeida, L. S., \& Franco, A. (2010). Psychological tests and assessment in Portugal. Testing International, 24, 6. 
Retrieved from http://www.intestcom.org/upload/sitefiles/ 61.pdf.

Almeida, L. S., Prieto, G., Muñiz, J., \& Bartram, D. (1998). O uso dos testes em Portugal, Espanha e Países Iberoamericanos [Tests use in Portugal, Spain and Ibero-American countries]. Psychologica, 20, 41-55.

Alvarez, A. (1972). Psicodiagnóstico clínico. Las técnicas de exploración psicológica [Clinical diagnosis: Techniques for psychological explanation]. Madrid, Spain: Aguillar.

American Educational Research Association, American Psychological Association, National Council on Measurement in Education (1999). Standards for educational and psychological testing. Washington, DC: American Educational Research Association.

Ávila Espada, A., \& Rodríguez, C. (1992). Psicodiagnóstico clínico [Clinical psychodiagnosis]. Madrid, Spain: Eudema Universidad.

Carpintero, H. (1989). La evolución psicodiagnóstica en España. [The psychodiagnostic evolution in Spain]. Evaluación Psicopedagógica, 5(1), 3-21.

Casullo, M. (1996). Evaluación psicológica y Psicodiagnóstico [Psychological assessment and psychodiagnosis]. Buenos Aires, Argentina: UBA, Facultad de Psicología. Secretaría de Cultura. Serie Materiales de Cátedra.

Casullo, M., Figueroa, N., \& Aszkenazi, M. (1991). Teoría y Técnicas de Evaluación Psicológica [Theories and tecniques on psychological assessment]. Buenos Aires, Argentina: Psicoteca.

Contini, E. N. (2013). Valorización y desvalorización de los testes en el campo de la psicología argentina: Una disociación no superada [Appreciation and devaluation of tests in Argentinean psychology: An unsurpassed dissociation]. Revista Latinoaamericana de Ciencia Psicologia, 5(2), 119-122.

Diniz, A. M., Almeida, L. S., \& Pais, L. G. (2007). Contextos profissionais e práticas da avaliação psicológica: Inquérito aos psicólogos Portugueses [Professional contexts and psychological practices: A survery among Portuguese psychologists]. Psico-USF, 12, 1-12.

Ever, A., Muñiz, J., Bartram, D., Bobn, D., Egeland, J., Fernández-Hermida, J. R., ... Thomás, U. (2011). Testing practices in the 21st century: Developments and European psychologists' opinions. European Psychologist, 17, 300-319.

Geisinger, K. (2013). APA handbook of testing and assessment in psychology (Vol. 1-3). Washington, DC: American Psychological Association.

Gregory, R. J. (2010). Psychological testing: History, principles and applications. New York, NY: Pearson Higher Ed.

Hambleton, R., Bartram, D., \& Oakland, T. (2011). Technical advances and guidelines for improving testing practices. In P. R. Martin, F. M. Cheung, M. C. Knowles, M. Kyrios, L. Littlefield, J. B. Overmier, \& J. M. Prieto (Eds.), IAAP handbook of applied psychology. Malden, MA: WileyBlackwell.

Hutz, C. S. (2009). Avanços e polemicas em avaliacão psicológica [Advances and questions on psychological assessment]. Sao Paulo, Brazil: Casa do Psicologo.
Leach, M. M., \& Oakland, T. (2007). Ethics standards impacting test development and use: A review of 31 ethics codes impacting practices in 35 countries. International Journal of Testing, 7, 71-88.

Leon, C., Silva, M., De Llano, J. ( 2008). Test development. Paper presented at the Conference, Psicologia Hoy, at Andrés Bello Catholic University, Caracas, Venezuela

Muñiz, J., \& Bartram, D. (2007). Improving international tests and testing. European Psychologists, 12, 206-219.

Muñiz, J., \& Fernández-Hermida, J. R. (2000). La utilización de los tests en España [Test use in Spain]. Papeles del Psicólogo, $76,41-49$.

Muñiz, J., Bartram, D., Evers, A., Boben, D., Matesic, K., Glabeke, K., ... Zaal, J. R. (2001). Testing practices in European countries. European Journal of Psychological Assessment, 17, 201-211.

Oakland, T. (2004). Use of educational and psychological tests internationally. Applied Psychology: An International Review, 53, 157-172.

Oakland, T. (2009). How universal are test development and use?. In E. Grigorenko (Ed.), Assessment of abilities and competencies in an era of globalization (pp. 1-40). New York, NY: Springer.

Oakland, T., Wechsler, S. M., \& Maree, K. (2013). Test use with children across cultures: A view from three cultures. In K. F. Geisinger (Ed.), APA Handbook on testing and assessment in psychology. Testing and assessment in school psychology and education (Vol. 3, pp. 231-257). Washington, DC: American Psychological Association.

Pasquali, L. (2010). Instrumentos psicológicos: Teoria e pratica [Psychological instruments: Theory and practice]. Porto Alegre, Brazil: Artes Medicas.

Prieto, G., \& Muñiz, J. (2000). Un modelo para evaluar la calidad los tests utilizados en Espanã [A model to assess the quality of tests used in Spain]. Papeles del Psicólogo, 77, $65-71$.

Primi, R. (2010). Avaliação Psicologia no Brasil: Fundamentos, situação atual e direções para o futuro [Psychological assessment in Brazil: Background, present situation and future directions]. Psicologia, Teoria e Pesquisa, 26, 25-35.

Shiraev, E. (2011). A global perspective. Thousands Oak, CA: Sage.

Vivas, E.(2000). Assessment trends in Venezuela and Latin American. Paper presented at the 108th Annual Conference of the American Psychological Association, Washington, DC.

Wechsler, S. M. (2013). El movimiento para el desarrollo de los testes psicológicos en Brasil: Una experiencia pionera [Brazilian movement for developing psychological tests: A pioneer experience]. Revista Latinoamericana de Ciencia Psicologica, 5(2), 10-100.

Wechsler, S. M., Solíz, M. P., Ferreira, C., Magno, I., Contini, N., Blumen, S., ... Viloria, C. L. (2010). Test movement in Iberian Latin American countries. Testing International, 24, 7. Retrieved from http://www.intestcom.org/ upload/sitefiles/61.pdf. 